\title{
Comparative studies on the production of statins using different microbial strains
}

\author{
MAHIN BASHa Syed * \\ Biochemistry Laboratory, P.M. Sayeed Calicut University Centre, Lakshadweep, India
}

\begin{abstract}
In this study, we aimed to increase the yield of mevastatin and lovastatin in solid state fermentation (SSF) using three different fungi, Aspergillus terreus MTCC 279, Penicillium citrinum MTCC 1751, and Penicillium brevicompactum MTCC 549. Initially, we screened various substrates for maximizing the production of mevastatin and lovastatin, and barley powder was found to be the most suitable substrate for $A$. terreus. We applied response surface methodology (RSM) to determine the optimal parameters for initial moisture content, temperature, and inoculum size. The use of RSM resulted in maximizing the production of mevastatin to $288.13 \mathrm{mg} / \mathrm{gram}$ dry substrate (gds) and lovastatin to $329.51 \mathrm{mg} / \mathrm{gds}$. For further studies, we used the high yielding strain of $A$. terreus with barley as a substrate. In the validation experiment, the maximum amount of mevastatin $(297.98 \mathrm{mg} / \mathrm{gds})$ and lovastatin $(340.71 \mathrm{mg} / \mathrm{gds})$ was obtained using $A$. terreus with barley as a substrate. This is the first report on the simultaneous production of mevastatin and lovastatin using a high yielding strain in SSF.
\end{abstract}

Key words: solid state fermentation, mevastatin, Aspergillus terreus, Penicillium citrinum, Penicillium brevicompactum, response surface methodology

\section{Introduction}

Statins, a class of fungal secondary metabolites, have attracted considerable attention because of their ability to influence the de novo synthesis of endogenous cholesterol, which is $\sim 66 \%$ of the cholesterol in human body (Alberts, 1988). All statins possess a common main polyketide portion, i.e., a hydroxy-hexahydro naphthalene ring, to which different side chains are linked at $\mathrm{C} 6$ and C8. Lovastatin contains a methyl butyric side chain and a $\beta$-hydroxylactone, and the latter is present as the corresponding $\beta$-hydroxy acid in the pharmaceutically active drug.

Both mevastatin and lovastatin are derived from fungal sources, while pravastatin and simvastatin are chemical modifications of mevastatin and lovastatin, respectively (Chakravarti and Sahai, 2004; Alberts et al., 1980a). Mevastatin was first isolated as an antifungal metabolite from the fermentation broth of Penicillium brevicompactum in 1976 (Endo et al., 1977). Mevastatin was then commercially producing using Penicillium citrinum (Endo et al., 1977; Endo et al., 1986), and its production by solid state fermentation (SSF) was reported by Biocon using a large-scale solid matrix bioreactor (Suryanarayan et al., 2001); however, there is not much readily available information on the procedure that was followed by Biocon. Reducing the cost of fermentation by finding inexpensive and efficient substrates and optimization of the mode of fermentation is of high importance. Solid state fermentation (SSF) offers the advantage of using inexpensive agro-industrial residues as substrates, which also act as a support matrix and provide nutrients that are required for the growth of fungi. SSF provides higher yields compared to conventional submerged fermentation $(\mathrm{SmF})$ and provides a natural habitat for fungal organisms; moreover, it requires lower capital investment, generates a lower volume of polluting effluents, and requires minimal instrumentation (Perez-Guerra et al., 2003).

\footnotetext{
* Corresponding author: Biochemistry Laboratory, P.M. Sayeed Calicut University Centre, Androth Island, U.T of Lakshadweep-682551, India; e-mail: sdmahinbasha@gmail.com
} 
Lovastatin is formed when extracting mevinolinic acid from the cultivation media (Kumar et al., 2000; Barrios-González and Mejía, 2007; Bizukojc and Ledakowicz, 2009). Lovastatin, monacolin J, monacolin L, and mevastatin canbe produced from Monascus ruber (Endo, 1979), $P$. brevicompactum, and $A$. terreus (Alberts et al., 1980b). Moreover, fermentation-derived lovastatin acts as a precursor for simvastatin, which was obtained via the selective enzymatic deacylation of lovastatin (Daborah et al., 1992), and is a powerful semi-synthetic statin that is commercially available as Zocor ${ }^{\mathrm{TM}}$.

In this study, we evaluate the simultaneous production of mevastatin and lovastatin by three different microorganisms, i.e., $A$. terreus, $P$. citrinum, and $P$. brevicompactum, in SSF using various substrates. The simultaneous production of mevastatin and lovastatin, allows reduction in space, time, and the amount of medium used for fermentation. We further optimized it with the best microorganism (A. terreus) and substrate (barley powder) using response surface methodology (RSM), which is a powerful and an efficient mathematical approach that is extensively applied for optimizing the fermentation process (Syed et al., 2014). RSM provides information about the interaction between process parameters as well as information that is necessary for both design and process optimization. We optimized the factors that have significant effects on production (initial moisture content, incubation temperature, and inoculum size) using a central composite design (CCD) and response surface analysis. The effects of process parameters, such as the initial moisture content, temperature and inoculum volume, were investigated using RSM.

\section{Materials and methods}

\section{Media components}

We purchased potato dextrose agar (PDA), glucose, malt extract, magnesium sulfate, and manganese sulfate from Hi-Media Limited, India. All substrates for SSF were purchased from local markets located at Chidambaram, Tamil Nadu, India. HPLC-grade acetonitrile (ACN) and ethanol were purchased from Rankem, New Delhi, India. All chemicals (Hi-Media, Mumbai, India) were of analytical grade. Mevastatin was purchased from Sigma Chemicals, Bangalore, India, and pharmaceutical grade lovastatin (lactone form) tablets containing $40 \mathrm{mg}$ of lovastatin per tablet were obtained from Merck Laboratories.

\section{Culture maintenance}

For this study, $A$. terreus, $P$. citrinum, and $P$. brevicompactum were obtained from the Institute of Microbial Technology (MTCC), Chandigarh, India. The cultures were maintained on potato dextrose agar slants at $25^{\circ} \mathrm{C}$ for 12 days, and the slants were sub-cultured every 30 days. A spore suspension $\left(10^{6}\right.$ spores $\left./ \mathrm{ml}\right)$ prepared from such slants was used to inoculate $100 \mathrm{ml}$ of the sterile seed medium in $250 \mathrm{ml}$ flasks at $25^{\circ} \mathrm{C}, 120 \mathrm{rpm}$ for 2 days in an incubator shaker. We used the potato dextrose broth as a seed medium for all the three cultures/fungal strains that were tested.

\section{Fermentation procedure}

Fifteen different solid substrates such as besan flour, ragi flour, millet powder, rice flour, wheat bran, black gram powder, green gram powder, green peas powder, yellow peas powder, white bean powder, rice bran, long grain rice, barley powder, soya bean powder, and sago powder were individually screened using statin-producing microorganisms such as $A$. terreus, $P$. citrinum, and $P$. brevicompactum. The experiments were performed in $250 \mathrm{ml}$ Erlenmeyer flasks containing $5 \mathrm{~g}$ of a substrate with the initial moisture content of $66 \%(\mathrm{w} / \mathrm{w})$. The contents of the flasks were mixed and autoclaved at $121^{\circ} \mathrm{C}$ at 15 psi for $20 \mathrm{~min}$. The seed medium was inoculated with $10^{6}$ spores $/ \mathrm{ml}$ and incubated at $30^{\circ} \mathrm{C}$ for $48 \mathrm{~h}$. To inoculate the production medium, we used five percent of this preculture (glucose $(5 \mathrm{~g} / 100 \mathrm{ml})$, malt extract $(5 \mathrm{~g} / 100 \mathrm{ml})$, magnesium sulfate $(0.2 \mathrm{~g} / 100 \mathrm{ml})$, and manganese sulfate $(0.1 \mathrm{~g} / 100 \mathrm{ml}))$. Fermentation was performed at $30^{\circ} \mathrm{C}$ for all the three microorganisms, i.e., A. terreus, $P$. brevicompactum ( 7 days), and $P$. citrinum (10 days), but at different incubation times (Syed et al., 2015).

\section{Extraction of mevastatin and lovastatin}

After fermentation, to obtain the intracellular product, the cultures were harvested and homogenized (using a motor pestle). For the analysis, a total of $2 \mathrm{~g}$ of dry substrate (dried in an oven) was used: $1 \mathrm{~g}$ from the fermentate was used to extract mevastatin and $1 \mathrm{~g}$ was used to extract lovastatin. We added equal volumes of ethanol to the substrates, and the suspensions were maintained in a rotary shaker that was incubated for $1 \mathrm{~h}$ at $200 \mathrm{rpm}$ at $40^{\circ} \mathrm{C}$. The suspension was filtered using a Whatman filter paper, and then through a micro filter 
(Millipore) having a pore diameter of $0.22 \mu \mathrm{m}$. Furthermore, using HPLC, we analyzed $20 \mu \mathrm{l}$ of the filtrates for mevastatin and lovastatin.

\section{HPLC analysis of mevastatin and lovastatin}

Both mevastatin and lovastatin were analyzed in a Shimadzu HPLC (LC20 AT prominence) at $238 \mathrm{~nm}$ in the Luna C18 column having an ID of 250X $4.6 \mathrm{~mm}$, UV detector (SPD $20 \mathrm{~A}$ ) and a column oven (CTO-10 AS VP) at $45^{\circ} \mathrm{C}$. The binary gradient system was used and the samples were manually injected using the Rheodyne injector of $20 \mu \mathrm{l}$. As the mobile phase, we used acetonitrile and $0.1 \%$ orthophosphoric acid in a $60: 40$ ratio. The eluent was pumped at a flow rate of $1.5 \mathrm{ml} / \mathrm{min}$. For the standard curve, various concentrations of $20,40,80$, 100 , and $120 \mu \mathrm{g}$ of mevastatin were dissolved in acetonitrile and analyzed using HPLC. The equation of the standard curve for the various concentrations of mevastatin $(Y)$ versus the peak area $(X)$ was $Y=49870 X$ with $R^{2}=0.9952$. Similarly, for the standard curve, various concentrations of lovastatin dissolved in acetonitrile were prepared and analyzed using HPLC. The equation of the standard curve for the various concentrations of lovastatin $(Y)$ versus the peak area $(X)$ was $Y=44250 X$ with $R^{2}=0.993$. During fermentation, lovastatin was produced as a mixture of lactone and free $\beta$-hydroxy acid form; therefore, the standards were prepared in both forms. Note that the retention time of lovastatin in its beta hydroxyacid form is $8 \mathrm{~min}$.

\section{Results}

\section{The screening of solid substrates in SSF} using $A$. terreus, $P$. citrinum, and $P$. brevicompactum

The selection of a substrate for the SSF process depends primarily on its cost and availability and may involve screening of several starchy substrates that are locally available. Compared to $\mathrm{SmF}$, the availability of water in substrates is an important factor in SSF. A lower moisture content within the substrate limits the growth and metabolism of the microorganisms. Note that barley powder was found to be the best substrate (Tables 1-3).

Comparison of $A$. terreus, $P$. citrinum, and $P$. brevicompactum efficiency in mevastatin and lovastatin production from different substrates

When barley flour was used as a substrate, $A$. terreus yielded $272.16 \mathrm{mg} / \mathrm{gds}$ (grams of dry substrate) of mevastatin and $206.8 \mathrm{mg} / \mathrm{gds}$ of lovastatin, followed by
Table 1. Results of various solid substrates for the production of mevastatin and lovastatin using $A$. terreus

\begin{tabular}{l|c|c}
\hline \multicolumn{1}{c|}{ Substrates } & $\begin{array}{c}\text { Lovastatin } \\
{[\mathrm{mg} / \mathrm{gds}]}\end{array}$ & $\begin{array}{c}\text { Mevastain } \\
{[\mathrm{mg} / \mathrm{gds}]}\end{array}$ \\
\hline Green peas & 13.3 & 122.28 \\
\hline Long grain rice & 71.76 & 110.92 \\
\hline Ragi & 148.32 & 69.92 \\
\hline Barley powder & 206.8 & 272.16 \\
\hline Beans & 19.08 & 75.24 \\
\hline Sago powder & 80.6 & 90 \\
\hline Green gram & 4.48 & 74.36 \\
\hline Besan flour & 9.6 & 70.36 \\
\hline White bean powder & 2.32 & 67.48 \\
\hline Millet & 0.48 & 71.24 \\
\hline Rice bran & 2.04 & 68.16 \\
\hline Yellow peas & 56.68 & 82.24 \\
\hline Rice flour & 30.31 & 81.6 \\
\hline Wheat bran & 5.36 & 72.64 \\
\hline
\end{tabular}

Table 2. Results of various solid substrates for the production of mevastatin and lovastatin using $P$. citrinum

\begin{tabular}{l|c|c}
\hline \multicolumn{1}{c|}{ Substrates } & $\begin{array}{c}\text { Lovastatin } \\
{[\mathrm{mg} / \mathrm{gds}]}\end{array}$ & $\begin{array}{c}\text { Mevastain } \\
{[\mathrm{mg} / \mathrm{gds}]}\end{array}$ \\
\hline Green peas & 0 & 0 \\
\hline Long grain rice & 2.87 & 74.87 \\
\hline Black gram & 11.96 & 68.44 \\
\hline Ragi & 31.92 & 217.05 \\
\hline Barley powder & 8.16 & 75.92 \\
\hline Beans & 10.64 & 71.52 \\
\hline Sago powder & 1.96 & 0 \\
\hline Green gram & 0.4 & 66.76 \\
\hline Besan flour & 2.52 & 0 \\
\hline White bean powder & 0 & 0 \\
\hline Millet & 0 & 72.6 \\
\hline Rice bran & 0 & 0 \\
\hline Yellow peas & 0.44 & 0 \\
\hline Rice flour & 0 & 70.4 \\
\hline Wheat bran & 4.92 & 66.96 \\
\hline
\end{tabular}

$110.92 \mathrm{mg} / \mathrm{gds}$ of mevastatin and $71.76 \mathrm{mg} / \mathrm{gds}$ of lovastatin for long grain rice (Table 1 ). Note that $A$. terreus produced mevastatin in almost all the substrates that were tested. As shown in Table 1, barley $(288.13 \mathrm{mg} / \mathrm{gds}$ 
Table 3. Results of various solid substrates for the production of mevastatin and lovastatin using $P$. brevicompactum

\begin{tabular}{l|c|c}
\hline \multicolumn{1}{c|}{ Substrates } & $\begin{array}{c}\text { Lovastatin } \\
{[\mathrm{mg} / \mathrm{gds}]}\end{array}$ & $\begin{array}{c}\text { Mevastain } \\
{[\mathrm{mg} / \mathrm{gds}]}\end{array}$ \\
\hline Green peas & 0 & 0 \\
\hline Long grain rice & 0 & 0 \\
\hline Black gram & 0 & 0 \\
\hline Ragi & 3.64 & 125.07 \\
\hline Barley powder & 6.52 & 68.72 \\
\hline Beans & 0 & 0 \\
\hline Sago powder & 0 & 0 \\
\hline Green gram & 0 & 0 \\
\hline Besan flour & 0 & 0 \\
\hline White bean powder & 0 & 0 \\
\hline Millet & 0 & 67.12 \\
\hline Rice bran & 3.64 & 68.6 \\
\hline Yellow peas & 0 & 0 \\
\hline Rice flour & 1.36 & 67.36 \\
\hline Wheat bran & 0 & 0 \\
\hline
\end{tabular}

of mevastatin and $329.51 \mathrm{mg} / \mathrm{gds}$ of lovastatin) and long grain rice ( long grain rice is four to five times as long as normal rice) were found to be better than other substrates that were used for mevastatin and lovastatin production. Hence, we performed further parameter optimization for $A$. terreus using barley as a substrate.

Among the fungal stains that were tested, $P$. citrinum resulted in the maximum mevastatin production of $217.05 \mathrm{mg} / \mathrm{gds}$ and lovastatin production of $31.92 \mathrm{mg} / \mathrm{gds}$ when ragi flour was used as a substrate (Table 2). P. citrinum was tested with 15 different substrates, but only few showed a positive result for mevastatin and lovastatin production, whereas other substrates afforded poor yields. $P$. citrinum showed better yield for mevastatin compared to $P$. brevicompactum for ragi flour. The second highest mevastatin and lovastatin production levels were obtained for barley powder, i.e., $75.92 \mathrm{mg} / \mathrm{gds}$ and $8.16 \mathrm{mg} / \mathrm{gds}$, respectively. Note that the maximum production levels were obtained after 10 days of incubation.

$P$. brevicompactum produced mevastatin and lovastatin in only five of the tested substrates: ragi flour, barley powder, millet, rice bran, and rice flour. Note that the highest amounts of mevastatin and lovastatin were produced when $P$. brevicompactum was grown in a me- dium where ragi flour was used as a substrate (Table 3 ). Furthermore, compared to $A$. terreus and $P$. citrinum, $P$. brevicompactum was the weakest producer of mevastatin and lovastatin. The above results demonstrate that the three microorganisms that were tested have different incubation periods, and the maximum yield of mevastatin and lovastatin production was achieved in 7 days for $A$. terreus, 10 days for $P$. citrinum, and 7 days for $P$. brevicompactum.

A. terreus was superior in mevastatin and lovastatin production compared to the other two microorganisms that were tested. $P$. citrinum produced more mevastatin and lovastatin compared to $P$. brevicompactum. All the three microorganisms produced higher titers of mevastatin and lovastatin in starch-rich substrates. $P$. citrinum and $P$. brevicompactum produced a maximum yield in the same substrate (ragi), whereas $A$. terreus produced the maximum yield in barley powder. Table 3 shows $P$. brevicompactum grown on all the substrates, but the production is negligible. In almost all the substrates, $P$. citrinum growth was observed; however, poor production of mevastatin and lovastatin was observed in only a few of them such as green peas, sago powder, besan flour, white bean powder, rice bran, and yellow peas (Table 1 ). Note that $A$. terreus is a potential producer of lovastatin and the same $A$. terreus was used for producing mevastatin; thus, it has shown dominance over the other two microorganisms (Syed et al., 2015).

\section{Optimization of mevastatin and lovastatin production using Response surface methodology}

To optimize the production of mevastatin and lovastatin using RSM, we studied the effect of various process parameters such as initial moisture content, incubation temperature, and inoculum size. Based on initial experimental results ( 3 fungal strains and 15 substrates), further optimization was performed using the high yielding stain of $A$. terreus and barley powder as a substrate. Note that these process parameters have considerable influence on the fungal growth and secondary metabolite production. To determine the optimum for each significant variable, we applied a full factorial central composite design $\left(2^{3}\right)$ and RSM. To identify the optimum levels for different process parameters influencing mevastatin and lovastatin production, SSF was performed in conical flasks containing previously optimized nutrients. We studied the individual and inter- 
Table 4. Experimental range and levels of the independent variables for A.terreus

\begin{tabular}{c|c|c|c|c|c|c}
\hline Variables & $\begin{array}{c}\text { Media } \\
{[\mathrm{g} / \mathrm{l}]}\end{array}$ & -1.682 & -1 & 0 & +1 & +1.682 \\
\hline$X_{1}$ & temperature & 21.6 & 25 & 30 & 35 & 38.4 \\
\hline$X_{2}$ & moisture content & 1 & 3 & 6 & 9 & 11 \\
\hline$X_{3}$ & inoculum size & 1 & 3 & 6 & 9 & 11 \\
\hline
\end{tabular}

Table 5. Full factorial central composite design matrix of three variables in coded and natural units along with the observed responses

\begin{tabular}{|c|c|c|c|c|c|c|c|}
\hline \multirow[t]{2}{*}{ Runs } & \multirow[t]{2}{*}{ Temperature } & \multirow[t]{2}{*}{$\begin{array}{l}\text { Initial } \\
\text { moisture }\end{array}$} & \multirow[t]{2}{*}{$\begin{array}{l}\text { Innoculum } \\
\text { size }\end{array}$} & \multicolumn{2}{|c|}{$\begin{array}{c}\text { Mevastatin } \\
\text { [mg/gds] }\end{array}$} & \multicolumn{2}{|c|}{$\begin{array}{c}\text { Lovastatin } \\
{[\mathrm{mg} / \mathrm{gds}]}\end{array}$} \\
\hline & & & & experimental & predicted & experimental & predicted \\
\hline 1 & -1 & -1 & -1 & 227.71 & 228.019 & 312.92 & 286.783 \\
\hline 2 & 1 & -1 & -1 & 80.84 & 131.336 & 86.24 & 134.503 \\
\hline 3 & -1 & 1 & -1 & 83.05 & 123.784 & 8.93 & 84.004 \\
\hline 4 & 1 & 1 & -1 & 119.31 & 134.111 & 176.94 & 125.768 \\
\hline 5 & -1 & -1 & 1 & 98.41 & 127.021 & 8.28 & 95.352 \\
\hline 6 & 1 & -1 & 1 & 87.47 & 90.148 & 145.95 & 106.777 \\
\hline 7 & -1 & 1 & 1 & 68.32 & 61.236 & 2.52 & -9.842 \\
\hline 8 & 1 & 1 & 1 & 88.27 & 131.373 & 133.59 & 195.627 \\
\hline 9 & -1.682 & 0 & 0 & 67.4 & 51.124 & 17.83 & -38.383 \\
\hline 10 & 1.682 & 0 & 0 & 73.92 & 28.802 & 0.9 & 6.343 \\
\hline 11 & 0 & -1.682 & 0 & 265.63 & 237.746 & 291.73 & 267.401 \\
\hline 12 & 0 & 1.682 & 0 & 218.27 & 184.761 & 198.04 & 171.598 \\
\hline 13 & 0 & 0 & -1.682 & 246.02 & 203.719 & 270.59 & 260.529 \\
\hline 14 & 0 & 0 & 1.682 & 135.58 & 116.487 & 199.01 & 158.300 \\
\hline 15 & 0 & 0 & 0 & 281.8 & 280.991 & 309.75 & 306.767 \\
\hline 16 & 0 & 0 & 0 & 267.22 & 280.991 & 289.27 & 306.767 \\
\hline 17 & 0 & 0 & 0 & 278.24 & 280.991 & 293.62 & 306.767 \\
\hline 18 & 0 & 0 & 0 & 272.08 & 280.991 & 297.26 & 306.767 \\
\hline 19 & 0 & 0 & 0 & 287.94 & 280.991 & 312.48 & 306.767 \\
\hline 20 & 0 & 0 & 0 & 288.13 & 280.991 & 329.51 & 306.767 \\
\hline
\end{tabular}

active effects of process parameter (temperature, moisture content, and inoculums size) variables by conducting the fermentation run at randomly selected and different levels of all three factors (Table 4). The response was measured as mevastatin and lovastatin production levels. Moreover, to optimize the process parameters, 20 experiments with six replicates were performed. These conditions were tested at five coded levels, namely, $-1.682,-1,0,+1$ and +1.682 , which are listed in Table 4. The optimal levels of the selected variables were obtained by solving the regression equation using MATLAB and by analyzing the response surface and contour plots. Table 4 lists the coded values and the levels of the variables temperature, moisture content, and inoculum size. Table 5 lists the experimental and predicted values along with the CCD experimental design. A multiple regression analysis of the CCD experimental design yields the following quadratic polynomial equation for the biosynthesis for mevastatin and lovastatin: 


$$
\begin{aligned}
Y & =280.991-6.63657 x_{1}-15.7525 x_{2}-25.9340 x_{3}+ \\
& -85.2161 x_{12}-24.6559 x_{22}-42.7402 x_{32}+26.7525 x_{1} x_{2}+ \\
& +14.9525 x_{1} x_{3}+9.61250 x_{2} x_{3} \\
Y & =306.767+13.2972 x_{1}-28.4822 x_{2}-30.3930 x_{3}+ \\
& -114.123 x_{12}-30.8536 x_{22}-34.4192 x_{32}+48.5113 x_{1} x_{2}+ \\
& +40.9262 x_{1} x_{3}+24.3963 x_{2} x_{3}
\end{aligned}
$$

Tables $6 \mathrm{~A}$ and $6 \mathrm{~B}$ list the results of the regression analysis from the data of central composite design experiments. The analysis of variance of the quadratic regression model demonstrated that in Eq. ( 1 and 2$)$ was a highly significant. It is evident from the Fisher's $F$-test with a very low probability value $[(P$ model $>F)=$ 0.0001]. To check the significance of each coefficient, Student's $t$-test and $P$ values were used as tools, which also indicated the interaction strength between each independent variable. The larger the magnitude of the $t$-value and the smaller the $P$ value, the more significant was the corresponding coefficient. Tables 7A and 7B list the analysis of variance for mevastatin and lovastatin production by $A$. terreus. The linear effect of $x_{3}$ and the squared effect of $x_{12}, x_{22}$, and $x_{32}$ were found to be significant as the $P$ value was less than 0.05 for mevastatin (Table 7A). Note that the squared effect of $x_{12}$ and $x_{32}$ and the interactive effect of $x_{1} x_{2}$ were found to be significant as the $P$ value was less than 0.05 for lovastatin (Table 7B). The correctness of fit of the model based on RSM can be verified by the coefficient of determination $\left(R^{2}\right)$, which provides a measure of how much the variation in the observed response values can be explained via experimental factors and their interactions. The closer the $R^{2}$ value is to 1 , the stronger the model, and the better it can predict the response. In this case, the value of the determination coefficient $\left(R^{2}=91.29 \%\right)$ indicated that only $8.71 \%$ of the total variations were not explained by the model for mevastatin. Moreover, the value of the determination coefficient $\left(R^{2}=89.23 \%\right)$ indicated that only $10.77 \%$ of the total variations were not explained by the model for lovastatin. This model resulted in six response surface plots (3D) with their corresponding contour plots (2D). The response surface plots with the contours of the calculated model for mevastatin and lovastatin production were generated by the Design-Expert software and are shown in Figure $1(\mathrm{~A}, \mathrm{~B}$, and $\mathrm{C}$ ) and Figure $2(\mathrm{~A}, \mathrm{~B}$, and $\mathrm{C})$. Three-dimensional graphs were generated from the pairwise combination of the three fac- tors, and elliptical contours were obtained when there was a perfect interaction between the substrates. Figure 1 ( $\mathrm{A}, \mathrm{B}$ and $\mathrm{C}$ ) shows the contour and response surface plot of the temperature, moisture content, and inoculum size for the mevastatin production at a fixed substrate concentration. The elliptical contour indicated greater interaction among the independent variables. The response surface plot and the contour plot shown in Figure $2(\mathrm{~A}, \mathrm{~B}$, and $\mathrm{C})$ show the effects of temperature, inoculum size, and moisture content. The elliptical contour indicated an interaction among the variables $x_{1}, x_{2}$, and $x_{3}$ for lovastatin production at a fixed substrate concentration.

\section{Effect of temperature on mevastatin and lovastatin production levels}

We performed experiments with five different temperature ranges $\left(21.6,25,30,35\right.$, and $\left.38.4^{\circ} \mathrm{C}\right)$ using RSM. The results of the study suggested that the temperature had influenced the mevastatin and lovastatin production by $A$. terreus. When the experimentation was carried out at $30^{\circ} \mathrm{C}$, any further increase in temperature lead to a decrease in mevastatin and lovastatin production (Tables 1 and 2).

\section{Effect of initial moisture on mevastatin and lovastatin production levels}

We used an initial moisture content of $66 \%$ for mevastatin and lovastatin production. The moisture content influenced the production of mevastatin and lovastatin. An increase in the moisture content to above optimal levels (moisture content $4.52 \mathrm{ml}$ ) caused aeration problems. A decrease in the moisture content below optimal levels led to poor growth in the fungal strain and lower productivity. Note that the optimum moisture content depends on the nature of microorganisms and the substrate that was used.

\section{Effect of inoculum size on mevastatin and lovastatin production levels}

The inoculum volume influenced the production levels of mevastatin and lovastatin. First, the inoculum volume (5 ml) was kept constant for all three microorganisms. The inoculum volume (48-h old) used in RSM was as follows: $1,3,6,9$, and $11 \mathrm{ml}$. The optimal inoculum volume was found to be $4.82 \mathrm{ml}$ for $A$. terreus, and the $48 \mathrm{~h}$ seed growth culture supported the maximum production with mevastatin and lovastatin yield for $A$. terreus. 
Table 6A. Estimated regression coefficients for mevastatin production by $A$. terreus

\begin{tabular}{l|c|c|c|c}
\hline \multicolumn{1}{c|}{ Term } & Coefficient & $\begin{array}{c}\text { Standard error } \\
\text { of coefficient }\end{array}$ & $t$-value & $P$-value \\
\hline Constant & 280.991 & 15.202 & 18.484 & 0.000 \\
\hline $\mathrm{A}$ & -6.637 & 10.086 & -0.658 & 0.525 \\
\hline $\mathrm{B}$ & -15.753 & 10.086 & -1.562 & 0.149 \\
\hline $\mathrm{C}$ & -25.934 & 10.086 & -2.571 & 0.028 \\
\hline $\mathrm{A}{ }^{*} \mathrm{~A}$ & -85.216 & 9.819 & -8.679 & 0.000 \\
\hline $\mathrm{B}{ }^{*} \mathrm{~B}$ & -24.656 & 9.819 & -2.511 & 0.031 \\
\hline $\mathrm{C}{ }^{*} \mathrm{C}$ & -42.740 & 9.819 & -4.353 & 0.001 \\
\hline $\mathrm{A}{ }^{*} \mathrm{~B}$ & 26.752 & 13.178 & 2.030 & 0.070 \\
\hline $\mathrm{A}^{*} \mathrm{C}$ & 14.953 & 13.178 & 1.135 & 0.283 \\
\hline $\mathrm{B}{ }^{*} \mathrm{C}$ & 9.613 & 13.178 & 0.729 & 0.482 \\
\hline
\end{tabular}

$R^{2}=91.29 \%$

Table 6B. Estimated regression coefficients for lovastatin production by $A$. terreus

\begin{tabular}{l|c|c|c|c}
\hline \multicolumn{1}{c|}{ Term } & Coefficient & $\begin{array}{c}\text { Standard error } \\
\text { of coefficient }\end{array}$ & $t$-value & $P$-value \\
\hline Constant & 306.77 & 22.98 & 13.348 & 0.000 \\
\hline $\mathrm{A}$ & 13.30 & 15.25 & 0.872 & 0.404 \\
\hline $\mathrm{B}$ & -28.48 & 15.25 & -1.868 & 0.091 \\
\hline $\mathrm{C}$ & -30.39 & 15.25 & -1.993 & 0.074 \\
\hline $\mathrm{A}{ }^{*} \mathrm{~A}$ & -114.12 & 14.84 & -7.688 & 0.000 \\
\hline $\mathrm{B}{ }^{*} \mathrm{~B}$ & -30.85 & 14.84 & -2.079 & 0.064 \\
\hline $\mathrm{C}{ }^{*} \mathrm{C}$ & -34.42 & 14.84 & -2.319 & 0.043 \\
\hline $\mathrm{A}^{*} \mathrm{~B}$ & 48.51 & 19.92 & 2.435 & 0.035 \\
\hline $\mathrm{A}^{*} \mathrm{C}$ & 40.93 & 19.92 & 2.054 & 0.067 \\
\hline $\mathrm{B}^{*} \mathrm{C}$ & 24.40 & 19.92 & 1.225 & 0.249 \\
\hline
\end{tabular}

$R^{2}=89.23 \%$

\section{Validation of the models}

The validation experiment was carried out in a $250 \mathrm{ml}$ Erlenmeyer flask under the optimum combination of the process parameters predicted by the polynomial model. The optimum values predicted by the model for mevastatin were as follows: temperature $29.23^{\circ} \mathrm{C}$, moisture content $4.52 \mathrm{ml}$, and inoculum size $4.82 \mathrm{ml}$. The maximum mevastatin production of $290.156 \mathrm{mg} / \mathrm{gds}$ was predicted by the model. In fact, we obtained mevastatin production of $297.98 \mathrm{mg} / \mathrm{gds}$, which is even higher than the predicted production level, thereby validating the proposed model. The optimum values predicted by the model for lovastatin were as follows: temperature $28.04^{\circ} \mathrm{C}$, moi- sture content $2.38 \mathrm{ml}$, and inoculum size $2.68 \mathrm{ml}$. The maximum response of $338.22 \mathrm{mg} / \mathrm{gds}$ of lovastatin production was predicted using this model. Moreover, using the predicted model, the lovastatin production of $340.71 \mathrm{mg} / \mathrm{gds}$ was obtained, which is also higher than the predicted values.

\section{Discussion}

A substrate that provides all the required nutrients to the microorganism for an enhanced yield of the product could be considered as an ideal substrate (Pandey et al., 2001). Glucose, a form of starch present in the tested 
Table 7A. Analysis of variance for mevastatin production by $A$. terreus

\begin{tabular}{|c|c|c|c|c|c|c|}
\hline Source & $\begin{array}{c}\text { Degree } \\
\text { of freedom }\end{array}$ & $\begin{array}{c}\text { Sum } \\
\text { of squares }\end{array}$ & $\begin{array}{l}\text { Mean } \\
\text { square }\end{array}$ & $F$-value & $P$-value & Source \\
\hline Regression & 9 & 145700 & 145700 & 16189 & 11.65 & 0.000 \\
\hline Linear & 3 & 13176 & 13176 & 4392 & 3.16 & 0.073 \\
\hline A & 1 & 602 & 602 & 602 & 0.43 & 0.525 \\
\hline B & 1 & 3389 & 3389 & 3389 & 2.44 & 0.149 \\
\hline $\mathrm{C}$ & 1 & 9185 & 9185 & 9185 & 6.61 & 0.028 \\
\hline Square & 3 & 124271 & 124271 & 41424 & 29.82 & 0.000 \\
\hline$A^{*} \mathrm{~A}$ & 1 & 91882 & 104652 & 104652 & 75.32 & 0.000 \\
\hline $\mathrm{B}^{*} \mathrm{~B}$ & 1 & 6064 & 8761 & 8761 & 6.31 & 0.031 \\
\hline $\mathrm{C}^{*} \mathrm{C}$ & 1 & 26325 & 26325 & 26325 & 18.95 & 0.001 \\
\hline Interaction & 3 & 8253 & 8253 & 2751 & 1.98 & 0.181 \\
\hline$A * B$ & 1 & 5726 & 5726 & 5726 & 4.12 & 0.070 \\
\hline$A^{*} \mathrm{C}$ & 1 & 1789 & 1789 & 1789 & 1.29 & 0.283 \\
\hline $\mathrm{B}^{*} \mathrm{C}$ & 1 & 739 & 739 & 739 & 0.53 & 0.482 \\
\hline $\begin{array}{l}\text { Residual } \\
\text { error }\end{array}$ & 10 & 13893 & 13893 & 1389 & & \\
\hline Lack-of-fit & 5 & 13535 & 13535 & 2707 & 37.81 & 0.001 \\
\hline Pure error & 5 & 358 & 358 & 72 & & \\
\hline Total & 19 & 159594 & & & & \\
\hline
\end{tabular}

Table 7B. Analysis of Variance for lovastatin production by $A$. terreus

\begin{tabular}{l|c|c|c|c|c|c}
\hline \multicolumn{1}{c|}{ Source } & $\begin{array}{c}\text { Degree } \\
\text { of freedom }\end{array}$ & $\begin{array}{c}\text { Sum } \\
\text { of squares }\end{array}$ & $\begin{array}{c}\text { Mean } \\
\text { square }\end{array}$ & $F$-value & $P$-value & Source \\
\hline Regression & 9 & 263008 & 263008 & 29223 & 9.20 & 0.001 \\
\hline Linear & 3 & 26109 & 26109 & 8703 & 2.74 & 0.099 \\
\hline $\mathrm{A}$ & 1 & 2415 & 2415 & 2415 & 0.76 & 0.404 \\
\hline $\mathrm{B}$ & 1 & 11079 & 11079 & 11079 & 3.49 & 0.091 \\
\hline $\mathrm{C}$ & 1 & 12615 & 12615 & 12615 & 3.97 & 0.074 \\
\hline Square & 3 & 199912 & 199912 & 66637 & 20.99 & 0.000 \\
\hline $\mathrm{A}^{*} \mathrm{~A}$ & 1 & 171883 & 187692 & 187692 & 59.11 & 0.000 \\
\hline $\mathrm{B}{ }^{*} \mathrm{~B}$ & 1 & 10956 & 13719 & 13719 & 4.32 & 0.064 \\
\hline C C & 1 & 17073 & 17073 & 17073 & 5.38 & 0.043 \\
\hline Interaction & 3 & 36988 & 36988 & 12329 & 3.88 & 0.045 \\
\hline $\mathrm{A}^{*} \mathrm{~B}$ & 1 & 18827 & 18827 & 18827 & 5.93 & 0.035 \\
\hline A*C & 1 & 13400 & 13400 & 13400 & 4.22 & 0.067 \\
\hline $\mathrm{B}{ }^{*} \mathrm{C}$ & 1 & 4761 & 4761 & 4761 & 1.50 & 0.249 \\
\hline Residual error & 10 & 31752 & 31752 & 3175 & & \\
\hline Lack-of-fit & 5 & 30636 & 30636 & 6127 & 27.46 & 0.001 \\
\hline Pure error & 5 & 1116 & 1116 & 223 & & \\
\hline Total & 19 & 294760 & & & & \\
\hline
\end{tabular}




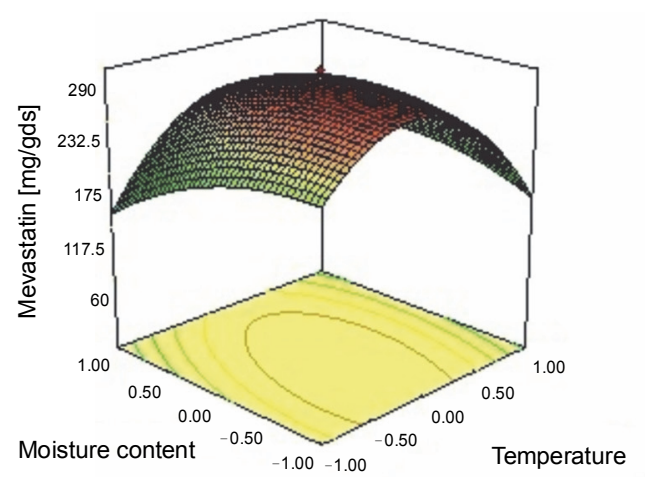

A

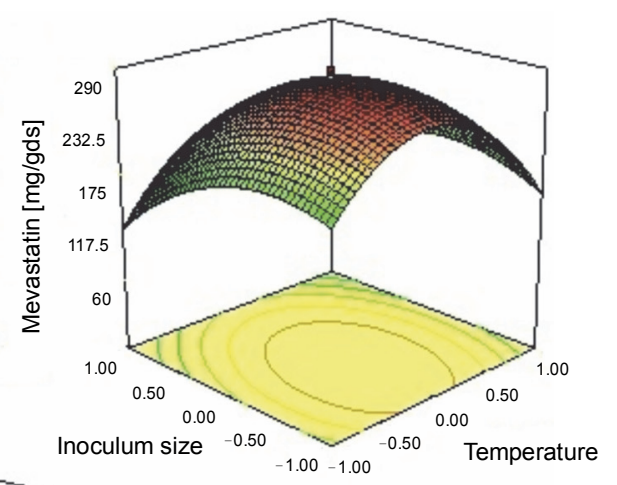

B

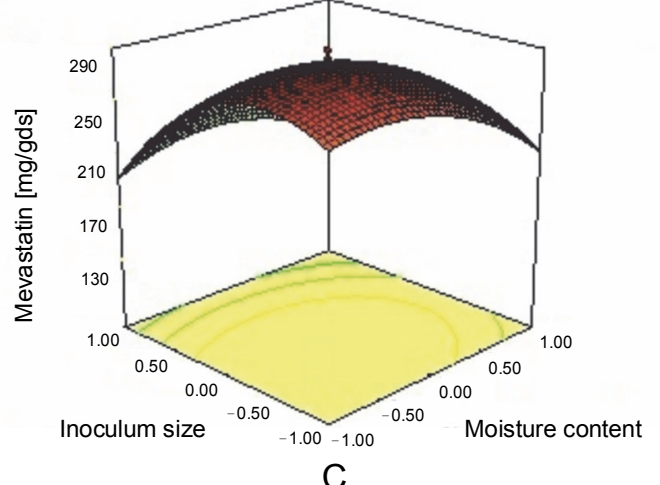

Fig. 1. A, B, C) response and contour plot showing the effects of interaction between the substrates temperature, moisture content and inoculum size for mevastatin

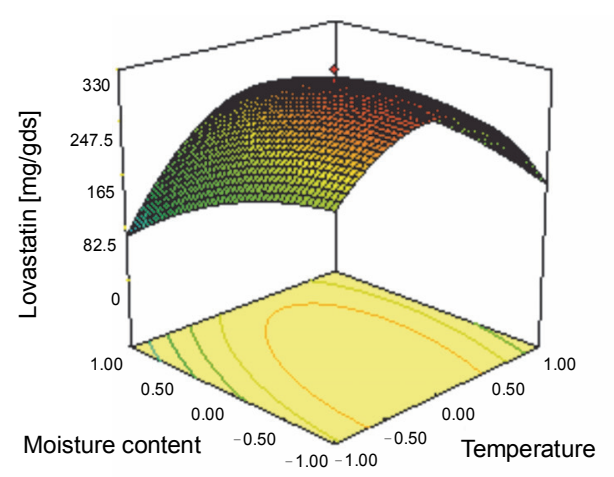

A

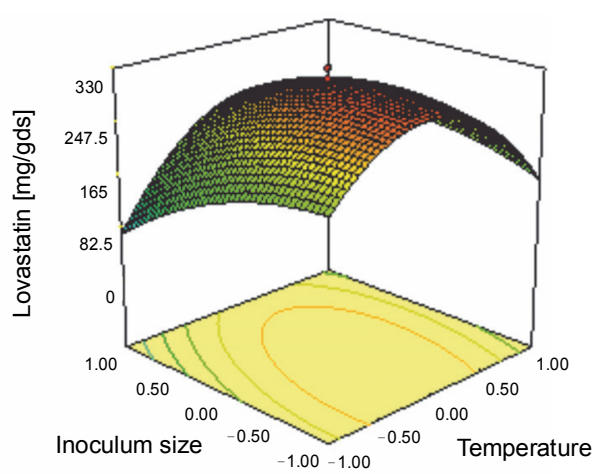

B

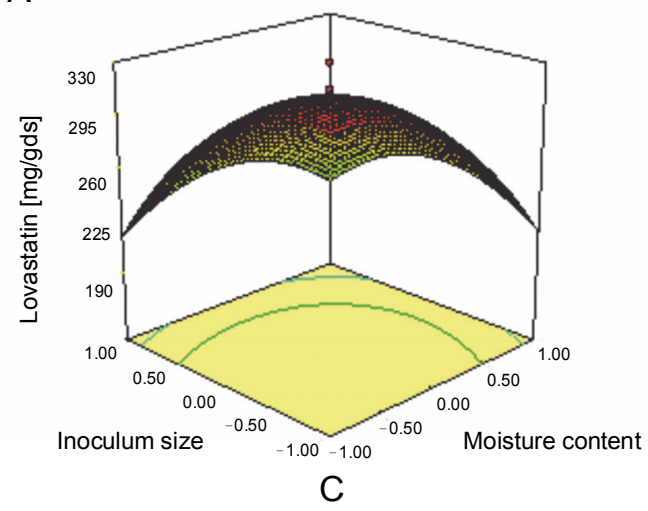

Fig. 2. A, B, C) response and contour plot showing the effects of the interaction between the substrates temperature, moisture content and inoculum size for lovastatin 
substrates, was found to be an excellent supplement for growth, possibly because of its rapid utilization by the fungal culture. However, the production of secondary metabolites has been found to be independent of growth (Drew and Wallis, 1983). Glucose, which is essential for growth, helps microorganisms to adapt to new environments. Once it is exhausted from the medium, the solid substrate (barley powder in this case) acted as a carbon source. SSF on inert supports is very convenient for microorganisms to grow and may help increase the production rate (Oojikaas et al., 2000). As described above, glucose was used as a nutrient supplement for the fungi to adapt to a new environment. Moreover, a solid substrate such as barley powder provided support for the microorganism to grow. Biocon produced lovastatin using $A$. terreus on wheat bran SSF (Suryanarayan, 2003). Note that a novel SSF process, using a high-density polyurethane foam (PUF) as an inert support, was developed for producing lovastatin nearly 10 years ago (Baños et al., 2009). A comparison of lovastatin yield of $19.95 \mathrm{mg} / \mathrm{gdc}$, obtained using SSF with PUF, resulted in 30 times higher levels than those obtained using liquid submerged fermentation (SmF; $0.57 \mathrm{mg} / \mathrm{ml}$ ) (Baños et al., 2009). In this study, SSF resulted in a higher production of statins than SmF. Previously, RSM was used to optimize the culture medium for producing lovastatin by $M$. ruber and the maximum lovastatin yield obtained was $131 \mathrm{mg} / 1$ (Chang et al., 2002). The principal nutrients on the isolated Monascus pilosus mutant produced the highest level of lovastatin, i.e., $725 \mathrm{mg} / \mathrm{l}$ in the peptone medium containing glucose and glycerol (Miyake et al., 2006).

Higher yields of lovastatin, monacolin J, pravastatin, and mevastatin were produced by $A$. terreus strains compared to strains belonging to Monascus species (Manzoni and Rollini, 2002). A. terreus UV 1718 grown in a medium optimized by RSM and supplemented with mycological peptone produced a maximum of 3723.4 $\pm 49 \mu \mathrm{g} / \mathrm{g}$ DFM. The yield of lovastatin increased 2.6 -fold compared to production in un-optimized media (Pansuriya and Singhal, 2010). The maximum yield of lovastatin $(2.9 \mathrm{mg} / \mathrm{g}$ dry substrate) using rice as a substrate was reported by Wei et al. (2007) and was achieved by incubating $A$. terreus ATCC 20542 for 11 days at the following optimized SSF parameters: $50-60 \%$ initial moisture content, $\mathrm{pH} 5.5$, and incubation temperature $28^{\circ} \mathrm{C}$. A concentration of lovastatin of $6 \mathrm{mg} / \mathrm{g}$ was re- ported in the SSF of M. ruber as a result of adding soybean powder, glycerol, sodium nitrate, and acetic acid into the production medium (Xu et al., 2005). The optimal values for lovastatin were as follows: temperature $28.04^{\circ} \mathrm{C}$, moisture content $2.38 \mathrm{ml}$, and inoculum size $2.68 \mathrm{ml}$. In this study, we obtained a lovastatin production of $340.71 \mathrm{mg} / \mathrm{gds}$, which is higher than that reported previously (Syed et al., 2015).

To optimize the production of mevastatin by $P$. citrinum, the Plackett-Burman and central composite rotatable design have been used (Chakravarti and Sahai, 2002a). The optimization resulted in the production of $456 \mathrm{mg}$ of mevastatin. In another study, a mutant strain of $P$. citrinum grown in a chemically defined medium yielded $145 \mathrm{mg} / \mathrm{l}$ of mevastatin. Note that the addition of $\mathrm{KH}_{2} \mathrm{PO}_{4}$ into the production medium did not increase the mevastatin production, while the addition of a surfactant, Tween 80 , increased the mevastatin level to $175 \mathrm{mg} / \mathrm{l}$ (Chakravarti and Sahai, 2002b). The optimum values for mevastatin production obtained in this study were as follows: temperature $29.23^{\circ} \mathrm{C}$, moisture content $4.52 \mathrm{ml}$, and inoculum size $4.82 \mathrm{ml}$. The amount of mevastatin produced was $297.98 \mathrm{mg} / \mathrm{gds}$, which was higher than that reported in the literature.

The production of mevastatin by $P$. brevicompactum WA 2315 has been previously optimized using SSF (Shaligram et al., 2009). The feeding of glycerol (20\% $\mathrm{v} / \mathrm{v}$ ) into the growth medium on day 3 resulted in further improvement of mevastatin yield to $1406 \mu \mathrm{g} / \mathrm{gds}$. A twofold higher mevastatin concentration $(1200 \mathrm{mg} / \mathrm{l})$ than the control (without the addition of Triton X 100) has been reported by Choi et al. (2004) at the $10^{\text {th }}$ day of fermentation. An increase in mevastatin (ML-236B) production was also achieved by introducing a whole mevastatin biosynthetic gene cluster or the regulatory gene mlcR into the $P$. citrinum high-production mevastatin strain (Baba et al., 2009). In this case, glycerol was the most significant contributor to the mevastatin production rate. In another study, the addition of supplements at specific concentrations (glycerol $3.86 \mathrm{mg} / 100 \mathrm{ml}, \mathrm{CuCl}_{2} \cdot 2 \mathrm{H}_{2} \mathrm{O}$ $0.102 \mathrm{mg} / 100 \mathrm{ml}, \mathrm{FeSO}_{4} \cdot 7 \mathrm{H}_{2} \mathrm{O} 0.036 \mathrm{mg} / 100 \mathrm{ml}, \mathrm{K}_{2} \mathrm{HPO}_{4}$ $0.003 \mathrm{mg} / 100 \mathrm{ml}$ and $\mathrm{MgSO}_{4} \cdot 7 \mathrm{H}_{2} \mathrm{O} 0.09 \mathrm{mg} / 100 \mathrm{ml}$ ) resulted in a mevastatin production of $771 \mu \mathrm{g} / \mathrm{gds}$ (Shaligram et al., 2008).

The moisture content has an important role in SSF, although fermentation with relatively no moisture to very high initial moisture levels has been reported (Prior 
et al., 1992). However, it has been observed that high moisture content leads to the aggregation of substrate particles, poor aeration, and an occurrence of anaerobic conditions, while very low moisture content restricts fungal growth (Gervais and Molin, 2003). The optimal values of initial moisture content were determined at $4.52 \mathrm{ml}$ for mevastatin and $2.38 \mathrm{ml}$ for lovastatin, which resulted in the maximum levels of lovastatin and mevastatin production.

\section{Conclusions}

In this study, we focused on the simultaneous production of mevastatin and lovastatin, which act as excellent platforms for an industrial scale production. The most significant result of this study was the adoption of easily available starchy substrates for producing mevastatin and lovastatin using fungal strains of $P$. citrinum, $P$. brevicompactum, and $A$. terreus. In the fermentative production of mevastatin and lovastatin, ragi flour was found to be ideal for $P$. citrinum, and $P$. brevicompactum and barley powder proved to be the best substrate for $A$. terreus. Among the three microorganisms that were tested, the higher yielding microorganism $A$. terreus was selected for further parameter optimization using RSM. Under optimal conditions, the maximum mevastatin $(288.13 \mathrm{mg} / \mathrm{gds})$ and lovastatin $(329.51 \mathrm{mg} / \mathrm{gds})$ yields were achieved for $A$. terreus. In the validation experiment, the amount of mevastatin produced was $297.98 \mathrm{mg} / \mathrm{gds}$ and lovastatin of $340.71 \mathrm{mg} / \mathrm{gds}$ for A. terreus.

\section{References}

Alberts A.W., Chen J., Kuron G., Hunt V., Huff J., Hoffman C., Rothrock J., Lopez M., Joshua H., Harris E., et al. (1980a) Mevinolin: a highly potent competitive inhibitor of hydroxymethylglutaryl-coenzyme $A$ reductase and a cholesterol lowering agent. Proc. Natl. Acad. Sci. USA. 77: 3957-3961.

Alberts A.W., Chen J., Kuron G., Hunt V. (1980b) Mevinolin: a highly potent competitive inhibitor of hydroxymethylglutaryl-coenzyme $A$ reductase and a cholesterol-lowering agent. Proc. Natl Acad. Sci. USA: 77: 3957-3961.

Alberts A.W. (1988) Discovery, Biochemistry and biology of lovastatin. Am. J. Cardiol. 62: 10-15.

Baba S., Abe Y., Suzuki T., Ono C., Iwamoto K., Nihira T., Hosobuchi M. (2009) Improvement of compactin (ML236B) production by genetic engineering in compactin high-producing Penicillium citrinum. Appl. Microbiol. Biotechnol. 83: 697-704.
Baños J.G., Tomasini A., Szakács G., Barrios-González J. (2009) High lovastatin production by Aspergillus terreus in solid-state fermentation on polyurethane foam: an artificial inert support. J. Biosci.Bioeng. 108 (2): 105-110.

Barrios-González J., and Mejía A. (2007) Production of antibiotics and other commercially valuable secondary metabolites. [in:] Current developments in solid-state fermentation. Eds. Pandey A., Larroche C., Soccol C.R., RodríguezLeón J.A. Chapter 14, Springer, London, Heidelberg: 262-296.

Bizukojc M., Ledakowicz S. (2009) Physiological, morphological and kinetic aspects of lovastatin biosynthesis by Aspergillus terreus. Biotechnol. J. 4: 647-664.

Chakravarti R., Sahai V. (2002a) Optimization of compactin production in chemically defined production medium by Penicillium citrinum using statistical methods. Process Biochem. 38: 481-486.

Chakravarti R., Sahai V. (2002b) A chemically-defined medium for production of compactin by Penicillium citrinum. Biotechnol. Lett. 24: 527-530.

Chakravarti R., Sahai V. (2004) Compactin - a review. Appl. Microbiol. Biotechnol. 64: 618-624.

Chang Y.N., Huang J.C., Lee C.C., Shih I.L., Tzeng Y.M. (2002) Use of response surface methodology to optimize culture medium for production of lovastatin by Monascus ruber. Enzyme Microbial Technol. 30: 889-894.

Choi D., Cho K., Cha W.S., Ryu S.R. (2004) Effect of Triton X100 on compactin production from Penicillium citrinum. Biotechnol. Bioprocess Eng. 9: 171-178.

Daborah R.A., Lein J., Conder M.J., Tewalt G.L. (1992) Enzymatic deacylation of simvastatin. British Patent GB2255974.

Drew S.W., Wallis D.A. (1983) Regulation of secondary metabolism and keys to its manipulation. [in:] Secondary metabolism and differentiation in fungi. Marcel Dekker, NewYork: 35.

Endo A., Kuroda M., Terahara A., Yoshio T., Chhiro T. (1977) Physiologically active substances and fermentative process for producing the same. US Patent 4,049,495.

Endo A., Hasumi K., Yamada A., Shimoda R., Takeshima H. (1986) The synthesis of compactin (ML-236B) and monacolin $K$ in fungi. J. Antibiot. 39: 1609-1610.

Endo A. (1979) Monacolin K, a new hypocholesterolemic agent produced by a Monascus species. J. Antibiot. 32: 852-854.

Gervais P., Molin P. (2003) The role of water in solid-state fermentation. Biochem. Eng. J. 13: 85-101.

Kumar M.S. Jana S.K., Senthil V., Shashanka S., Kumar S.V., Sadhukhan A.K. (2000) Repeated fed-batch process for improving lovastatin production. Process Biochem. 36: 363-368.

Manzoni M., Rollini M. (2002) Biosynthesis and biotechnological production of statins by filamentous fungi and application of these cholesterol-lowering drugs. Appl. Microbiol. Biotechnol. 58(5): 555-564.

Miyake T., Uchitomi K., Zhang M.Y., Kono I., Nozaki N., Sammoto H., Inagaki K. (2006) Effects of the principal nu- 
trients on lovastatin production by Monascus pilosus. Biosci. Biotechnol. Biochem. 70(5): 1154-1159.

Oojikaas L.P., Weber F.J., Buitelaar R.M., Tramper J., Rinzema A. (2000) Defined media and inert supports: their potential as solid-state fermentation production systems. Trends Biotechnol. 18: 356-360.

Pandey A., Szakacs G., Soccol C.R., Rodriguez-Leon .J.A., Soccol V.T. (2001) Production, purification and properties of microbial phytases. Bioresource Technol. 77: 203-214.

Pansuriya R.C., Singhal R.S. (2010) Response surface methodology for optimization of production of lovastatin by solid state fermentation. Braz. J. Microbiol. 41: 164-172.

Perez-Guerra N., Torrado-Agrasar A., Lopez-Macias C., Pastrana L. (2003) Main Characteristics and applications of solid substrate fermentation. EJEAFChem. 2: 1-8.

Prior B.A., Preez J.C.D., Rein P.W. (1992) Environmental parameters. [in:] Solid substrate cultivation. Elsevier, London. pp. 65.

Shaligram N.S., Singh S.K., Singhal R.S., Szakacs G., Pandey A. (2008) Compactin production in solid-state fermentation using orthogonal array method by P. brevicompactum. Biochem. Eng. J. 41: 295-300.

Shaligram N.S., Singh S.K., Singhal R.S., Pandey A., Szakacs G. (2009) Compactin production studies using Penicillium brevicompactum under solid-state fermentation conditions. Appl. Biochem. Biotechnol. 159(2): 505-520.
Suryanarayan S., Sircar A., Khedkar A.P., Subramaniyam P., Tambe S.P., Anand K.N.S., Ramkrishna M., Ramavana G. (2001) Novel process for the manufacture and purification of compactin. WO, 081611.

Suryanarayan S. (2003) Current industrial practice in solid state fermentations for secondary metabolite production; the Biocon India experience. Biochem. Eng. J. 13: 189-195.

Syed M.B., Seraman S., Rajendran A., Thangavelu V. (2014) Valorization of agricultural residues for compactin production by Aspergillus terreus MTCC 279 in mixed substrate solid state fermentation. Waste Biomass Valorization 5: 715-724.

Syed M.B., Rajasimman M. (2015) Fermentative production and optimization of mevastatin in submerged fermentation using Aspergillus terreus. Biotechnol. Rep. 6: 124-128.

Wei P., Xu Z., Cen P. (2007) Lovastatin production by Aspergillus terreus in solid-state fermentation. J. Zhejiang. Univ. Sci. A. 8(9): 1521-1526.

Xu J., Wang Q.J., Jia X.Q., Sung C.K. (2005) Enhanced Lovastatin production by solid state fermentation of Monascus rubber. Biotechnol. Bioprocess Eng. 10: 78-84. 